\title{
Comparison of two great Chile tsunamis in 1960 and 2010 using numerical simulation*
}

\author{
Ruizhi Wen ${ }^{1, \uparrow}$ Yefei Ren ${ }^{1}$ Xiaojun $\mathrm{Li}^{2}$ and Rong Pan ${ }^{3}$ \\ 1 Institute of Engineering Mechanics, China Earthquake Administration, Harbin 150080, China \\ 2 Institute of Geophysics, China Earthquake Administration, Beijing 100081, China \\ ${ }^{3}$ Nuclear and Radiation Safety Center, Ministry of Environmental Protection, Beijing 100082, China
}

\begin{abstract}
Great differences in hazard and losses were shown from two tsunamis, both generated in Chile, one in 1960 and the other in 2010. Numerical simulation was applied to the tsunami analysis. The fault dislocation of the seafloor was assumed to equal to the initial tsunami wave field, which can be calculated by the formula of fault dislocation in the elastic isotropic half-space. The linear long wave theory was used as the tsunami hydrodynamic model, and the finite difference method and leap-frog scheme were selected for solving the equations. The accuracy of the simulated results was verified by the observed data in five tide gauges. By means of two scenario tsunamis, the analytical results show that the earthquake magnitude, bathymetry in rupture zone and rapid release of warning information in 2010 tsunami are the main explanations of the aforementioned great difference.
\end{abstract}

Key words: Chile earthquake; tsunami; numerical simulation

CLC number: P315.9 Document code: A

\section{Introduction}

At 06:34, February 27, 2010 (UTC), a great earthquake occurred near Concepcion City, Chile, of which the epicenter was located at $35.826^{\circ} \mathrm{S}, 72.668^{\circ} \mathrm{W}$, the magnitude was $M_{\mathrm{W}} 8.8$ and focal depth was $35 \mathrm{~km}$. The earthquake generated a high-speed tsunami wave which propagated to circum-Pacific countries and regions. The first maximum amplitude was $2.16 \mathrm{~m}$, the second was $2.34 \mathrm{~m}$ measured by Valparaiso and Talcahuano tide gauge at Chile, and all other global gauges recording data were less than $2 \mathrm{~m}$. In history, another famous tsunami occurred in Chile as magnitude $M_{\mathrm{W}} 9.5$ on May 22,1960 , the maximum runup reached to $25 \mathrm{~m}$ (Bryant, 2008). The damage induced by this tsunami was huge, especially in Hawaii and Japan, but no casualties and low economic losses in 2010 tsunami at these locations.

On March 11, 2011, the Japanese Tohoku earthquake also triggered destructive tsunami wave which rose to maximum runup of $37.9 \mathrm{~m}$ high and resulted

\footnotetext{
* Received 4 July 2011; accepted in revised form 5 October 2011; published 10 October 2011.

† Corresponding author. e-mail: ruizhiwen@hotmail.com

(c) The Seismological Society of China and Springer-Verlag Berlin Heidelberg 2011
}

in the major devastation along a $1000 \mathrm{~km}$-length coastline in Japan. Even away from $17000 \mathrm{~km}$ the Chilean coastline recorded $2 \mathrm{~m}$ height waves as well. This event caused the nuclear radiation leakage which gave a safety whistle for Chinese and other nuclear infrastructure locating along coastline. In this paper, applying numerical simulation method, we investigated the difference between two Chilean tsunami by comparison of generation and propagation characteristics and this would give the lessons for Chinese tsunami disaster mitigation, especially nuclear infrastructure risk analysis.

\section{Tsunami hazard and losses}

The tsunami occurred in 1960 was one of the most destructive and widespread natural hazard events in the last century, and also resulted in establishment of the Pacific Tsunami Warning Center (PTWC). The earthquake magnitude came up to amazing $M_{\mathrm{W}} 9.5$, which was the largest recorded earthquake in earthquake history. The enormous water wall drowned thousands of people, and maximum runup was about $25 \mathrm{~m}$ in Chile, $6.4 \mathrm{~m}$ in Japan and $10.7 \mathrm{~m}$ in Hawaii, respectively, as shown in Table 1. 
Table 1 Disaster description of Chile tsunamis in 1960 and 2010

\begin{tabular}{|c|c|c|c|c|}
\hline \multirow{2}{*}{$\begin{array}{l}\text { Countries } \\
\text { or regions }\end{array}$} & \multicolumn{2}{|c|}{ Maximum wave height } & \multicolumn{2}{|c|}{ Hazard and losses } \\
\hline & 1960 & 2010 & 1960 & 2010 \\
\hline Chile & $25^{\mathrm{a}, \mathrm{c} ; 1}$ & $2.61^{\mathrm{c} ; 2}$ & $\begin{array}{l}1655 \text { deaths }{ }^{\text {e }} ; 550 \text { million } \\
\text { dollars lost caused by both } \\
\text { earthquake and tsunami }{ }^{d}\end{array}$ & $\begin{array}{l}521 \text { deaths by both earthquake and } \\
\text { tsunami } ; 30 \text { billion dollars lost } \\
\text { by earthquake primarily }{ }^{\mathrm{f}}\end{array}$ \\
\hline U.S. west coast & $3.7^{\mathrm{a} ; 1}$ & $0.66^{\mathrm{c} ; 2}$ & 3 death and 3 injured ${ }^{c}$ & $\begin{array}{l}\text { No reports and news about death, } \\
\text { injury and economic losses }\end{array}$ \\
\hline Hawaii & $10.6^{\mathrm{a}, \mathrm{e} ; 1}$ & $0.98^{c ; 2}$ & $\begin{array}{l}61 \text { deaths }{ }^{\mathrm{a} ; \mathrm{e}}, 540 \text { buildings } \\
\text { destroyed, } 24 \text { million dollars lost }{ }^{\text {a }}\end{array}$ & $\begin{array}{l}\text { No reports and news about death, } \\
\text { injury and economic losses }\end{array}$ \\
\hline Japan & $6.4^{\mathrm{a}, \mathrm{c} ; 1}$ & $0.82^{\mathrm{c} ; 2}$ & $\begin{array}{l}190 \text { deaths, } 50000 \text { homes washed, } \\
400 \text { million dollars lost }{ }^{\mathrm{a}}\end{array}$ & $\begin{array}{l}\text { No death and injury, } 30 \text { million } \\
\text { dollars lost }\end{array}$ \\
\hline Chinese mainland & $0.3^{b ; 1}$ & $\mathrm{~N} / \mathrm{A}$ & $\begin{array}{l}\text { Death, injury and economic losses } \\
\text { not be found in any literatures and } \\
\text { documents }\end{array}$ & No effect by tsunami \\
\hline
\end{tabular}

Note: a Bryant (2008); b Wang et al. (2005); c NGDC (National Geophysical Data Center of U.S.); d Atwater et al. (1999); e

USGS; ${ }^{\mathrm{f}}$ Internet. ${ }^{1}$ eyewitness or post-tsunami survey measurement; ${ }^{2}$ tide-gauge measurement.

However, the tsunami occurred in 2010 with the magnitude reaching to $M_{\mathrm{W}} 8.8$, produced much lower runup in several areas of Pacific Rim. About ten minutes later after the earthquake, the first tsunami warning alert was sent to Chile, Peru and Ecuador from PTWC. The warning information soon spread to Pacific Rim countries and regions for subsequent emergency measures. In Japan and America, the tsunami travel time and runup were rapidly estimated by numerical simulation method for evacuation planning. The rapid release of warning information also contributed to the limited damage from the 2010 tsunami at most places other than along the Chile coast. The first author had a postsurvey at Tome, a town near Concepcion in Chile, and it was clearly shown that the public knowledge of tsunami in Chile was abundant that the most of people evacuated to higher ground after the earthquake, without the specific tsunami warning.

\section{Characteristic comparisons}

\subsection{Bathymetry in rupture zone}

A common knowledge is that far-field tsunami amplitude is primarily dependent on the size of the scalar seismic moment, and the earthquake source parameters are the secondary influence factor. The average runup can be estimated by establishing statistical relationship with the moment magnitude and epicentral distance (Abe, 1979, 1981; Pelayo and Wiens, 1992). Applying numerical approximation of linear long-wave theory, the influence of source parameters including focal depth, fault length, width and dip can be evaluated by means of different focal models (Yamashita and Sato, 1974; Kajiura, 1981). Okal (1988) indicated that focal depth and geometry played only a limited role in controlling the amplitude of tsunami by considering normal mode theory. He explained minor contribution of focal depth on tsunami amplitude, and showed when seafloor displacement decreased with increasing focal depth, the displaced seafloor areas increased, which resulted in only a slight overall reduction in the volume of lifted water. Tanioka and Satake (1996) showed that horizontal fault deformation usually neglected had a significant contribution to the tsunami generation when tsunami source was located at the steep slope. Geist and Yoshioka (1996) proposed that slip orientation had a great effect on the directivity of tsunami. The location of inter-plate rupture area relative to the coastline was also an important factor of tsunamigenic earthquake. If the rupture zone underlies the continental shell, only part of vertical displacement field will be transferred to the tsunami (Geist, 1998).

It has been proven that nearshore tsunami heights were significantly affected by small-scale changes in bathymetry, especially in bays, harbors, and inlets (Satake, 1988; Rabinovich, 1997; Matsuyama, et al., 1999). In this paper we compared the bathymetry of rupture zone of the tsunami in 2010 with that in 1960, as shown in Figure 1. We inferred that bathymetry in rupture zone affected tsunami amplitude not only at local region but also over all areas covered by the tsunami. The 2010 tsunami rupture zone overlapped some land areas, 
and earthquake-releasing energy was absorbed by the movement of land uplift and subsidence, and not all of the energy was transferred to form the tsunami wave. However, the rupture zone of 1960 tsunami was mainly located in the deep ocean along Atacama Trench, which uplifted a wide range of water body to generate greater initial tsunami wave. This is one of reasons that the hazard from the 2010 tsunami was less than that from the 1960 one.

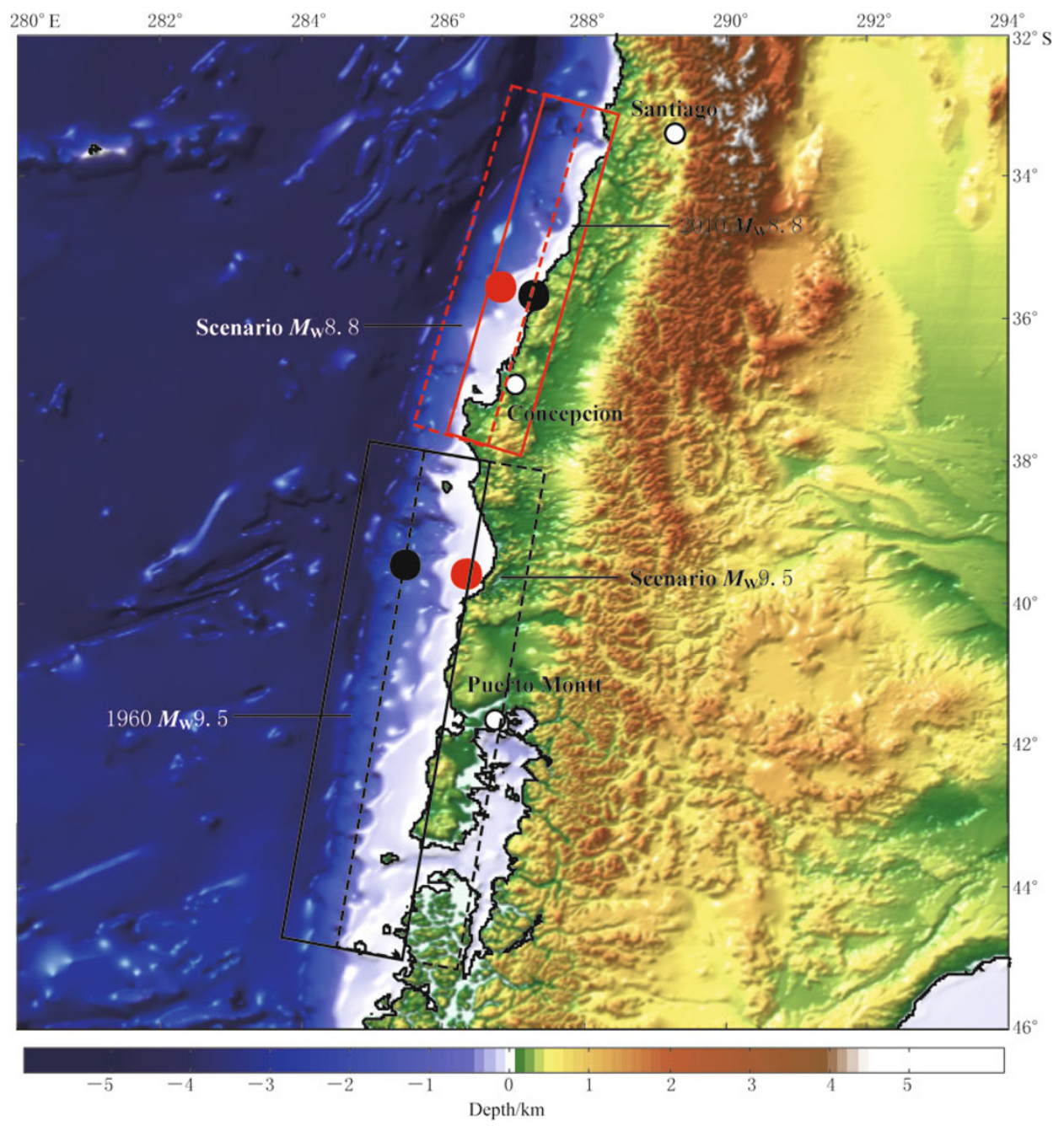

Figure 1 Comparison of bathymetry map between the earthquakes occurred in 1960 and 2010. The black solid line rectangle is the ruptured zone in 1960, and the red solid line rectangle is the one in 2010. The two dashed rectangles mean the scenario tsunamis which have the same fault ruptured parameters of two actual tsunamis in 1960 and 2010, just the different locations. The two black solid circles are the epicenters of actual tsunamis, while the two red solid circles are the scenario ones.

\subsection{Initial displacement}

For tsunami numerical simulation, the geometrical displacement of the seafloor is usually assumed to be the same as the initial tsunami wave field. Because the tsunami traveling velocity is much slower than fault rupture velocity, the time-history and directivity of fault rupture is usually neglected. Hence, the formula of fault dislocation in elastic isotropic half-space (Mansinha and
Smylie, 1971) can be used as shown in equation (1):

$$
u_{i}=\int_{\Sigma} \Delta u_{j}\left[\delta_{j k} \bar{\lambda} \frac{\partial u_{i}^{l}}{\partial \xi_{l}}+\bar{\mu}\left(\frac{\partial u_{i}^{j}}{\partial \xi_{k}}+\frac{\partial u_{i}^{k}}{\partial \xi_{j}}\right)\right] v_{k} \mathrm{~d} S,
$$

where, $\Delta u_{j}$ is the dislocation of the $j$ direction, $\delta_{j k}$ is the Kronecker symbol, $\bar{\lambda}$ and $\bar{\mu}$ are the Lamé coefficient, $v_{k}$ is the cosine angle between the normal direction of plane element $\mathrm{d} S$ and $k$ direction, $u_{i}^{j}\left(u_{i}^{k}, u_{i}^{l}\right)$ is the $i$ - 
directional displacement induced by that the $j(k, l)$ directional force acts on the point $\left(\xi_{1}, \xi_{2}, \xi_{3}\right), \xi_{j}\left(\xi_{k}\right.$, $\left.\xi_{l}\right)$ is the coordinate component of the point $\left(\xi_{1}, \xi_{2}, \xi_{3}\right)$.

When computing the elastic dislocation by the above numerical analysis, the fundamental fault parameters are commonly adopted from the publication$\mathrm{s}$ or the released information of the official departments and research institutes, and the estimation by means of empirical relationships. After the $M_{\mathrm{W}} 8.8$ earthquake occurred in Chile in 2010, the fault length and width were released by U.S. Geological Survey and the $W$ phase moment tensor solution were also published, including fault dip, strike, rake, depth and moment $M_{0}=2.0 \times 10^{22} \mathrm{~N} \cdot \mathrm{m}$. Then the average slip $\bar{D}$ was computed following the relationship $M_{0}=\mu \bar{D} L W$ (Somerville, et al., 1990). Of course, the best description of fault length and width may be decided by the spatial distribution of aftershocks. The aftershocks usually occur at the area relating to the spatial distribution of the main shock slip. To make the computation simple, the rectangle fault plane was used in this paper that is generally adopted by the most of tsunami simulation method.

All related parameter values are listed in the Table 2, as well as those of the $M_{\mathrm{W}} 9.5$ earthquake occurred in 1960 (Kanamori and Ciper, 1974).

Table 2 Focal mechanism and fault parameters of Chile Tsunamis in 1960 and 2010

\begin{tabular}{lcc}
\hline \multicolumn{1}{c}{ Parameters } & Tsunami in 2010 & Tsunami in 1960 \\
\hline Rupture length/km & 500 & 800 \\
Rupture width/km & 100 & 200 \\
Average slip/m & 13.3 & 25 \\
Dip ${ }^{\circ}$ & 14 & 10 \\
Rake $/{ }^{\circ}$ & 104 & 90 \\
Fault strike & $\mathrm{N} 16^{\circ} \mathrm{E}$ & $\mathrm{N} 10^{\circ} \mathrm{E}$ \\
Focal depth $/ \mathrm{km}$ & 35 & 33 \\
\hline
\end{tabular}

Consequently, the vertical displacement fields of the two great earthquakes could be calculated, and initial tsunami waves can be obtained based on aforementioned assumptions. Figure 2 shows the isoline of analytical dislocation and the sections along parallel and perpendicular fault-strike. The maximum uplift and subsidence are $5.14 \mathrm{~m}$ and $2.37 \mathrm{~m}$ of 2010 earthquake, respectively. And those of 1960 earthquake are $9.43 \mathrm{~m}$ and $5.28 \mathrm{~m}$, about two times of the former. The rup- tured area of the earthquake in 1960 is three times and the average slip is two times than those of the earthquake in 2010 due to the difference of the magnitude. The releasing energy of $M_{\mathrm{W}} 9.5$ earthquake can be 10 times than $M_{\mathrm{W}} 8.8$ one, using the magnitude-energy relationship $\log E=1.5 M+11.8$ developed by Gutenberg and Richter (Gutenberg, 1956). It also shows that all uplift and part of subsidence took place in coastal land so only part of water body is transferred to tsunami for 2010 tsunami.

\subsection{Tsunami Propagation}

Tsunami hydrodynamic model has been in debate in recent 30 years, due to great difference in estimating the amplitude of the leading waves when using Boussinesq equations and linear long wave theory. For the transoceanic tsunami, the ratio of the water depth to the wavelength should be in the order of $10^{2}$ and the wave steepness should be in order of $10^{-3}$. These values suggest that the linear long wave theory is a good first-order approximation (Shuto, 1991). In addition, it is an explicit equation for neglecting the dispersion and nonlinearity, only considering the Coriolis force induced by Earth rotation, which can be written in spherical coordinates as

$$
\begin{gathered}
\frac{\partial \eta}{\partial t}+\frac{1}{R \cos \theta}\left[\frac{\partial M}{\partial \lambda}+\frac{\partial}{\partial \theta}(N \cos \theta)\right]=0, \\
\frac{\partial M}{\partial t}+\frac{g h}{R \cos \theta} \frac{\partial \eta}{\partial \lambda}=f N, \\
\frac{\partial N}{\partial t}+\frac{g h}{R} \frac{\partial \eta}{\partial \theta}=-f M
\end{gathered}
$$

where $\eta$ is the water level above still wave; $\theta$ and $\lambda$ are the latitude and longitude, respectively; $M$ and $N$ are the water discharges in longitudinal and latitudinal directions, respectively (because of $\eta<<h, M=\mu h$ and $N=v h, \mu$ and $v$ are the average propagation velocity in longitudinal and latitudinal directions, respectively); $\mathrm{g}$ is the gravity acceleration; $h$ is the undisturbed sea depth; $R$ is the Earth's radius; $f$ is the Coriolis parameter $(f=2 \omega \sin \theta$, and $\omega$ is the frequency of the Earth's rotation).

The finite difference method was used for solving the above equations and the leap-frog scheme to improve its high-speed computation. The explicit expression of $\eta, M$, and $N$ are 

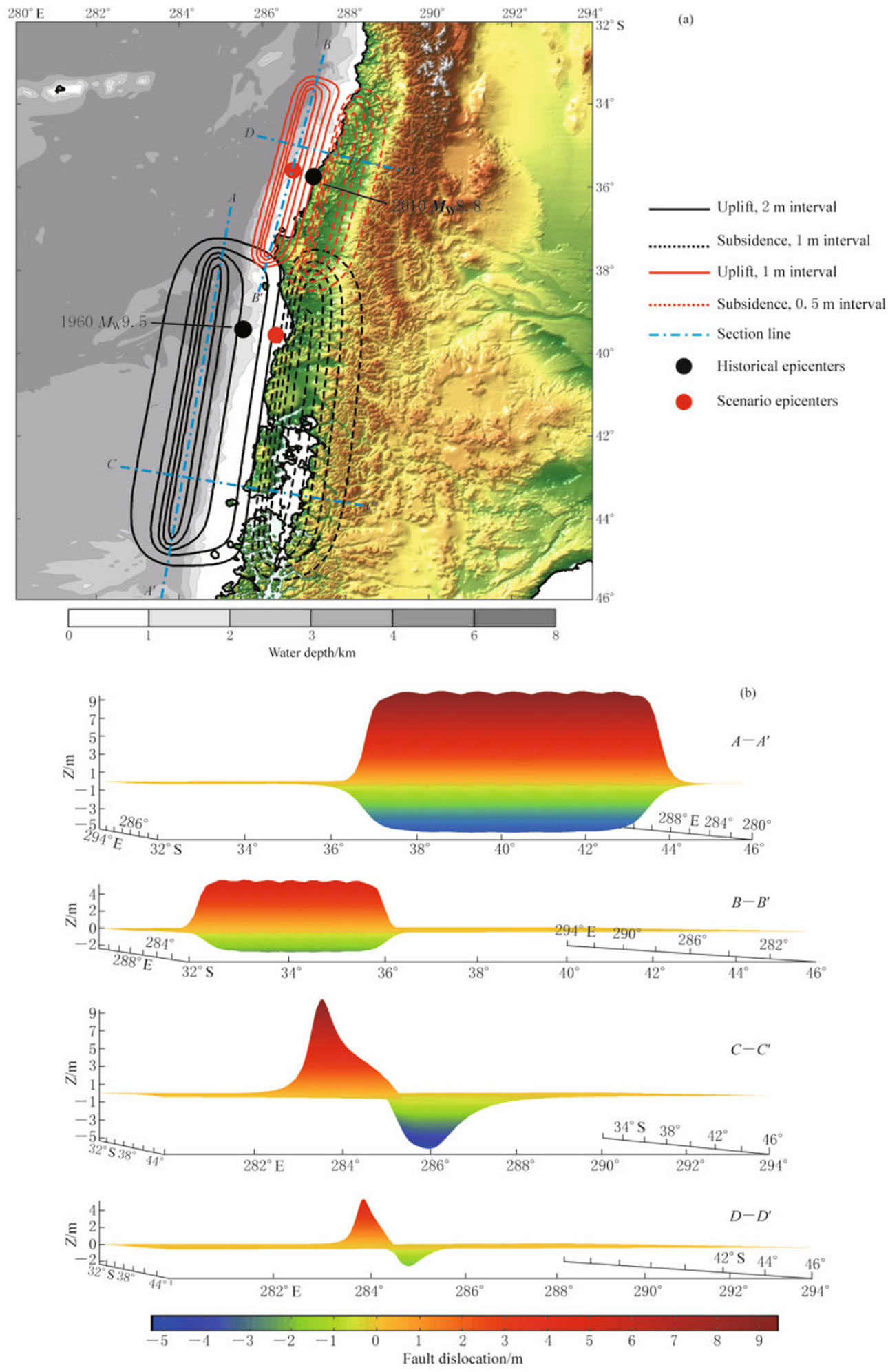

Figure 2 The initial seafloor vertical displacements of the Chile earthquakes occurred in 1960 and 2010 , respectively (a); Four sections of dislocation distribution which show the difference of the fault dislocation between two earthquakes clearly (b). The dislocation isoline of two great earthquakes, solid lines mean the uplift and dashed lines mean the subsidence. The rupture zone of the $M_{\mathrm{W}} 9.5$ earthquake is obviously larger than the one of the $M_{\mathrm{W}} 8.8$ earthquake, and the epicenter of the $M_{\mathrm{W}} 9.5$ earthquake is farther away from the coastline than that of the $M_{\mathrm{W}} 8.8$ one, which causes the more still water body was transferred to the initial tsunami wave in 1960. The two red filled circles are the epicenters of scenario tsunami, corresponding to Figure 1. 


$$
\begin{gathered}
\eta_{j, m}^{n+\frac{1}{2}}=\eta_{j, m}^{n-\frac{1}{2}}-R_{1}\left[M_{j+\frac{1}{2}, m}^{n}-M_{j-\frac{1}{2}, m}^{n}+N_{j, m+\frac{1}{2}}^{n} \cos \theta_{m+\frac{1}{2}}-N_{j, m-\frac{1}{2}}^{n} \cos \theta_{m-\frac{1}{2}}\right], \\
M_{j+\frac{1}{2}, m}^{n+1}=M_{j+\frac{1}{2}, m}^{n}-R_{2} h_{j+\frac{1}{2}, m}\left[\eta_{j+1, m}^{n+\frac{1}{2}}-\eta_{j, m}^{n+\frac{1}{2}}\right]+R_{3} N^{\prime}, \\
N_{j, m+\frac{1}{2}}^{n+1}=N_{j, m+\frac{1}{2}}^{n}-R_{4} h_{j, m+\frac{1}{2}}\left[\eta_{j, m+1}^{n+\frac{1}{2}}-\eta_{j, m}^{n+\frac{1}{2}}\right]-R_{5} M^{\prime} \\
N^{\prime}=\frac{1}{4}\left[N_{j+1, m+\frac{1}{2}}^{n}+N_{j+1, m-\frac{1}{2}}^{n}+N_{j, m+\frac{1}{2}}^{n}+N_{j, m-\frac{1}{2}}^{n}\right], \\
M^{\prime}=\frac{1}{4}\left[M_{j+\frac{1}{2}, m+1}^{n}+M_{j+\frac{1}{2}, m}^{n}+M_{j-\frac{1}{2}, m+1}^{n}+M_{j-\frac{1}{2}, m}^{n}\right],
\end{gathered}
$$

where $j$ and $m$ are the grid labels in latitudinal and longitudinal directions, respectively; $n$ is the time-step label; $R_{1}, R_{2}, R_{3}, R_{4}, R_{5}$, are the constants: $R_{1}=\Delta t /\left(R \cos \theta_{\mathrm{m}} \Delta s\right), R_{2}=\mathrm{g} \Delta t /\left(R \cos \theta_{m} \Delta s\right)$, $R_{3}=2 \Delta t \omega \sin \theta_{m}, R_{4}=\mathrm{g} \Delta t /(R \Delta s), R_{5}=2 \Delta t \omega \sin \theta_{m+1 / 2}$, $\Delta s=\Delta \theta=\Delta \lambda$. The land boundary is considered as stiffwall condition, which means the normal velocity at costal land is zero. The boundary condition on land is perfect reflection and the open ocean boundary is free transmission.

We set the numerical computation zone from $80^{\circ} \mathrm{S}$ to $80^{\circ} \mathrm{N}$ and from $90^{\circ} \mathrm{E}$ to $65^{\circ} \mathrm{W}$ and the spatial step was set as 5 min in latitudinal and longitudinal directions, and temporal calculating step was set as $10 \mathrm{~s}$, and the total numbers of completing grids were 4727581 . Figure 3 shows the amplitude distributions with tsunami travel times. It clearly shows that the amplitudes of the tsunami in 1960 were much larger than those of the tsunami in 2010. The travel time maps of one hour interval of two tsunamis were calculated, as shown in Figure 4 and the traveling map in computation zone is different between two tsunamis because of the difference of the earthquake location and magnitude.
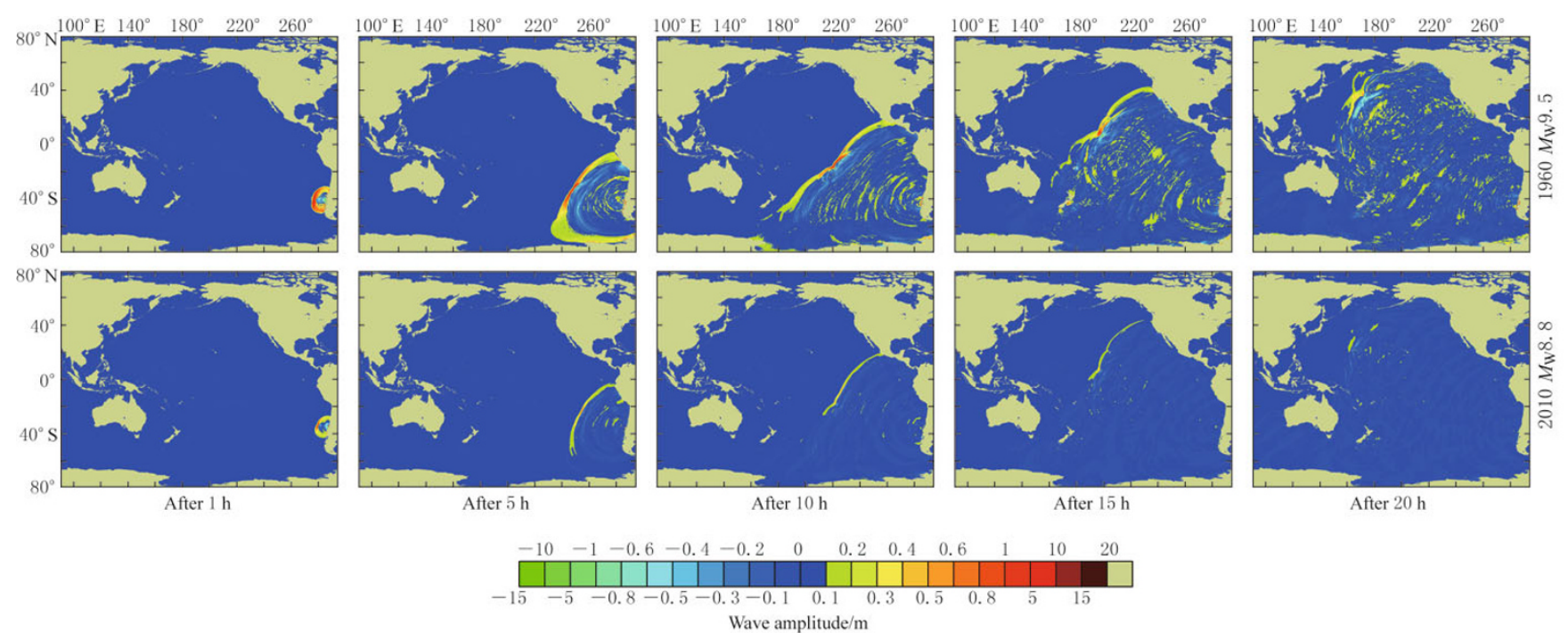

Figure 3 Wave amplitude snapshots of two tsunamis after 1, 5, 10, 15 and $20 \mathrm{~h}$.

For verifying the accuracy of the numerical simulation in 2010 tsunami, we outputted the computed tsunami wave time-histories at five tide gauges of which locations were marked in Figure 4. From the comparison results as shown in Figure 5, it can be easily found that the computed arrival time of the leading wave in all gauges match the observed data well, and the periodic amplitudes of computed time-histories are almost the same as those observed in Hanasaki of Japan and Kahului of Hawaii. Thus, it can be regarded as reasonable for our simulated results.

In order to roughly separate the bathymetry effect on the difference of wave amplitude and hazard loss between 1960 tsunami and 2010 tsunami, we created two scenario tsunamis, in which the $M_{\mathrm{W}} 8.8$ scenario is the 2010 tsunami to the offshore area, and $M_{\mathrm{W}} 9.5$ scenario 


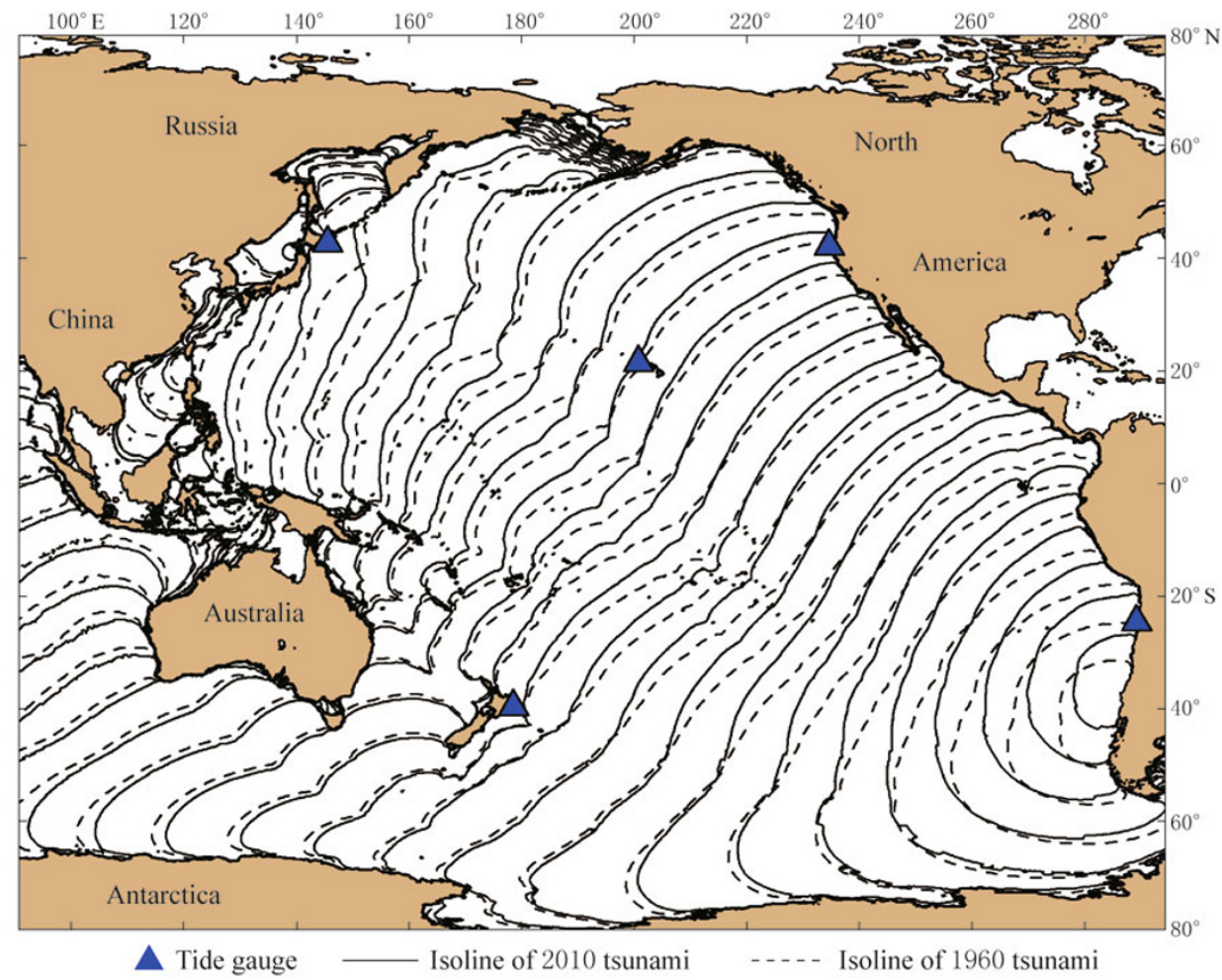

Figure 4 Travel time maps of two tsunamis (1h interval after the tsunami generated).
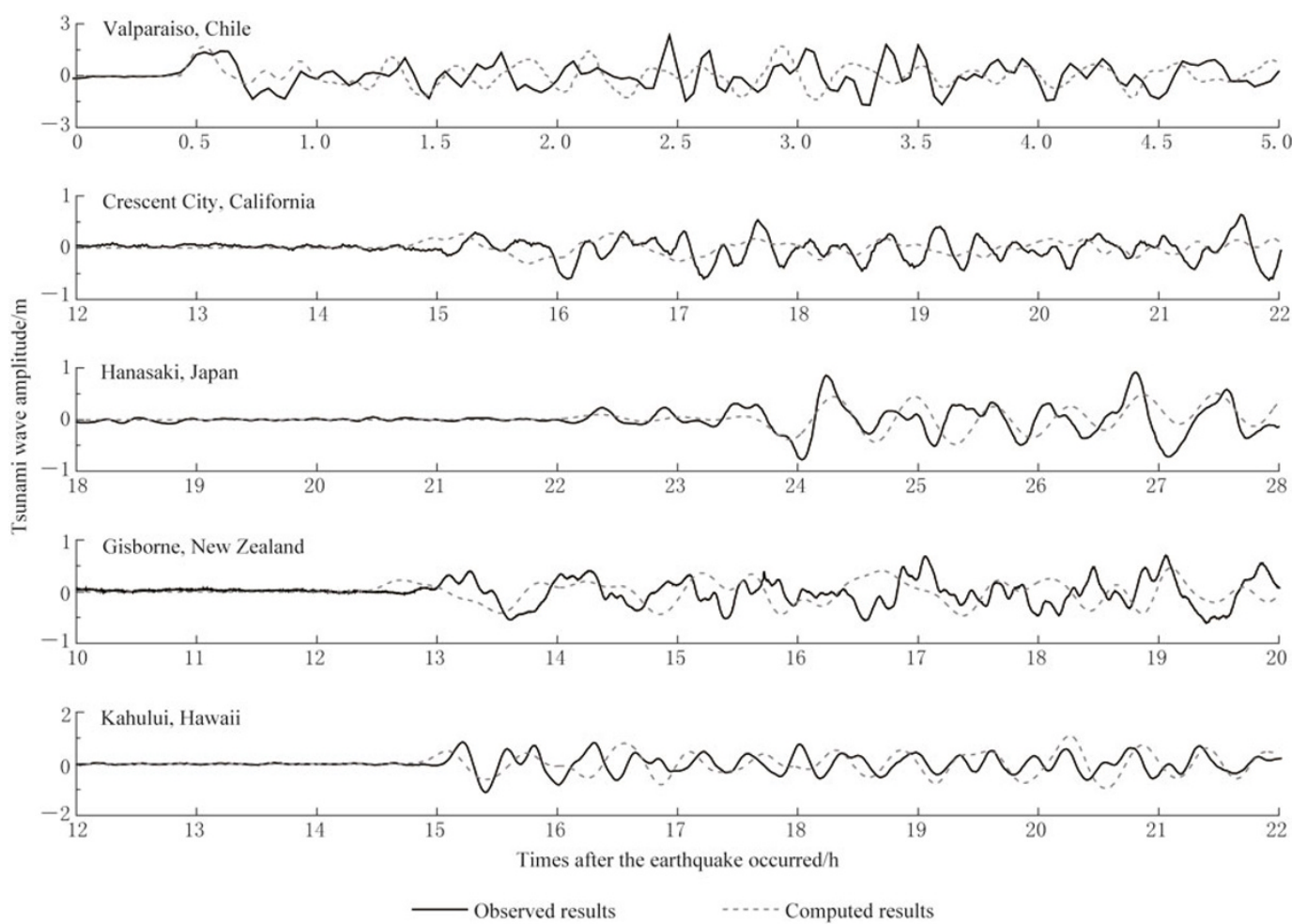

Figure 5 Comparison between observed and computed tsunami wave amplitude which occurred in 2010 at different tide gauges. 
is the 1960 tsunami to the nearshore area as shown in Figure 1.

The initial tsunami wave field should be quite different because of their different source locations where some part of displacement would be set as zero on the land areas. We calculated the initial raised water volume of two actual tsunamis and two scenario tsunamis, as shown in Table 3 . The computed results show that the actual 1960 earthquake generated almost 6 times initial raised water volume than the actual 2010 one, corresponding to their releasing energy difference. From Table 3 , it can be easily found that the movement of source to offshore area has contributed to $30 \%$ increased volume for the 2010 actual tsunami, while the movement to nearshore area has contributed to $20 \%$ decreased volume for the 1960 actual tsunami. Thus, it makes clear that the bathymetry has the significant effect on the tsunami wave generation.

Table 3 The initial raised water volume

\begin{tabular}{lcccc}
\hline \multirow{2}{*}{ Type } & \multicolumn{4}{c}{ Tsunami } \\
\cline { 2 - 5 } & Actual & Scenario & Actual & Scenario \\
& $M_{\mathrm{W}} 9.5$ & $M_{\mathrm{W}} 9.5$ & $M_{\mathrm{W}} 8.8$ & $M_{\mathrm{W}} 8.8$ \\
\hline Uplift $/\left(10^{10} \mathrm{~m}^{3}\right)$ & 127.3 & 109.3 & 22.6 & 23.6 \\
Subsidence $/\left(10^{10} \mathrm{~m}^{3}\right)$ & 18.6 & 5.7 & 2.3 & 9.0 \\
Total $/\left(10^{10} \mathrm{~m}^{3}\right)$ & 145.9 & 115.0 & 24.9 & 32.6 \\
\hline
\end{tabular}

\section{Conclusions}

We used hydrodynamic model to simulate two great tsunamis generated in Chile. To improve the calculating efficiency and save consuming time, the finite difference method was used in tsunami propagation simulation. The computed results were verified as being reliable by comparing them with the observed ones. Comparing the characteristics of the initial wave fields which were estimated by numerical computation, we concluded that the two main reasons of aforementioned difference between two tsunamis:

(1) The earthquake magnitude is an important factor influencing on tsunami wave amplitude for the initial tsunami generation. The discrepancy of the magnitude makes a great difference of the ruptured zone and the average slip, resulting in about two times difference of the maximum seafloor deformation and six times difference of the initial raised water volume.

(2) The bathymetry in ruptured zone has effect on the initial tsunami wave. The epicenter in 2010 earthquake approached to the coastline, parts of fault uplift areas and most of subsidence areas took place on the land, which leads to the decreased amount of initial sea water. The epicenter in 1960 is in the deep ocean and far away from the coastline and the initial raised water volume is controlled by the uplifted sea floor deformation, and a larger amount of still water was transferred to initial tsunami wave.

Acknowledgements The authors would like to thank the two anonymous reviewers for their comments that are helpful to improve the quality of manuscript. This work is supported by Environmental Protection Research Fund for Public Interest (No.201209040).

\section{References}

Abe K (1979). Size of great earthquake of 1837-1974 inferred from tsunami data. J Geophys Res 84(B4): 1 561-1 568.

Abe K (1981). Physical size of tsunamigenic earthquake of the northwestern Pacific. Phys Earth Planet Inter 27(3): 194-205.

Atwater B F, Cisternas M V, Bourgeois J, Dudley W C, Hendley J W and Stauffer P H compilers (1999). Surviving a Tsunami: Lessons From Chile, Hawaii, and Japan. U.S. Geological Survey Circular, 1187.

Bryant E (2008). Tsunami: The Underrated Hazard. Springer Verlag, Heidelberg, New York, 143-148.

Geist E L and Yoshioka S (1996). Source parameters controlling the generation and propagation of potential local tsunamis along the Cascadia margin. Natural Hazards 13(2): 151-177.

Geist E L (1998). Local tsunamis and earthquake source parameters. Advances in Geophysics 39: 117-209.

Gutenberg B (1956). The energy of earthquake. Quart J Geol Soc London 112: 1-14.

Kajiura K (1981). Tsunami energy in relation to parameters of the earthquake fault model. Bull Earthq Res Inst 56(3): 415-440.

Kanamori H and Ciper J J (1974). Focal process of the great Chilean earthquake, May 22, 1960. Phys Earth Planet Int 9: $128-136$.

Mansinha L and Smylie D (1971). The displacement field of inclined faults. Bull Seismol Soc Am 61(5): 1 433-1 440.

Matsuyama M, Walsh J P and Yeh H (1999). The effect of bathymetry on tsunami characteristics at Sissano Lagoon, Papua New Guinea. Geophys Res Lett 26(23): 3 513-3 516.

Okal E A (1988). Seismic parameters controlling far-field tsunami amplitudes: A review. Natural Hazards 1(1): 67-96.

Pelayo A M and Wiens D A (1992). Tsunami earthquakes: Slow thrust-faulting events in the accretionary wedge. $J$ Geophys Res 97(B11): 15 321-15 337.

Rabinovich A B (1997). Spectral analysis of tsunami waves: 
Separation of source and topography effects. $J$ Geophys Res 102(C6): 12 663-12 676.

Satake K (1988). Effects of bathymetry on tsunami propagation: Application of ray tracing to tsunamis. Pure Appl Geophys 126(1): 27-36.

Shuto N (1991). Numerical Simulation of Tsunamis: Its present and near future. Natural Hazards 4(2-3): 171191.

Somerville P, Irikura K, Somerville P, Irikura K, Graves R, Sawada S, Wald D, Abrahamson N, Iwasaki I, Kagawa I, Smity N and Kowada A (1999). Characterizing crustal earthquake slip models for prediction of strong ground motion. Seism Res Lett 70(1): 59-80.

Tanioka Y and Satake K (1996). Tsunami generation by horizontal displacement of ocean bottom. Geophys Res Lett 23(8): 861-864.

Wang F, Liu C S, Zhang Z Q (2005). Earthquake tsunami record in Chinese ancient books. Earthquake Research in China 21(3): 437-443.

Yamashita T and Sato R (1974). Generation of tsunami by a fault model. $J$ Phys Earth 22: 415-440. 